\title{
Comunicar en tiempos de crisis en las redes sociales. Estrategias de verificación e intermediación informativa en los casos de Facebook, Instagram y Twitter durante la COVID-19
}

\author{
Javier Bustos Díaz \\ Universidad de Málaga \\ bustos090@gmail.com \\ https://orcid.org/0000-0001-7932-7986
}

\author{
Francisco Javier Ruiz del Olmo \\ Universidad de Málaga \\ fjruiz@uma.es \\ https://orcid.org/0000-0002-1953-1798
}

\section{Communicating in times of crisis on social networks. Strategies for verification and information intermediation in the cases of Facebook, Instagram and Twitter during COVID-19}

La crisis sanitaria provocada por el virus conocido como COVID-19 ha representado un reto sin precedentes para nuestra sanidad, economía y también nuestro sistema mediático. En la era de la conectividad, la información juega papel esencial a la hora de ayudar a combatir la pandemia. En este sentido, las redes sociales pueden ayudar a difundir noticias de carácter sanitario o social, pero también se pueden convertir en uno de los mayores transmisores de desinformación, bulos y fake news. El presente trabajo analiza las principales herramientas que han empleado

Facebook, Instagram y Twitter para luchar contra estas noticias falsas. Las conclusiones iniciales revelan un acer-

camiento a estrategias y valores de tratamiento de la información del periodismo clásico, donde las redes sociales

actualizan la tradicional figura periodística del GateKeeper, creando filtros para las informaciones potencialmente falsas, así como advirtiendo a los usuarios de las mismas a través de mensajes insertados en la propia publicación entre otras técnicas.

\section{ABSTRACT}

The health crisis caused by the virus known as COVID-19 has represented an unprecedented challenge for our health, economy and also our media system. In the age of connectivity, information plays a vital role in helping to combat the pandemic. In this sense, social networks can help spread health or social news, but they can also become one of the greatest transmitters of disinformation, hoaxes and fake news. This paper analyses the main tools that Facebook, Instagram and Twitter have used to fight against these false news. The initial conclusions reveal an approach to information treatment strategies and values of classic journalism, where social networks update the traditional journalistic figure of the GateKeeper, creating filters for potentially false information, as well as warning users of the same through messages inserted in the publication itself, among other techniques.
PALABRAS CLAVE

Fake news; Facebook; Twitter; Instagram; Covid-19.
KEYWORDS

Fake news; Facebook; Twitter; Instagram; Covid-19. 


\section{Introducción}

En la sociedad actual la búsqueda y la distribución de la información se lleva a cabo en buena medida en redes sociales y en comunidades virtuales. Los medios tradicionales de información (prensa o televisión, por ejemplo) han perdido parte de su tradicional influencia en la agenda social. En este sentido es significativo cómo el Instituto Nacional de Estadística (2019) recoge que el $80,9 \%$ de los hogares con al menos un miembro de 16 a 74 años dispone de algún tipo de ordenador en 2019. Este porcentaje es 1,4 puntos superior al de 2018. Esta subida se debe, esencialmente, al aumento de dispositivos como las tablets, que se encuentran presentes en el $56,8 \%$ de los hogares.

Esta información se complementa con los datos proporcionados por el Estudio Anual Redes Sociales (2020), donde se matiza que del total de población española de entre 16 y 65 años, el 93\% son internautas esto es utilizan internet habitualmente, de los cuales el $87 \%$ son usuarios de redes sociales (Estudio Anual Redes Sociales, 2020). Además, el informe señala que el $70 \%$ de los usuarios declaran que los perfiles que más publicaciones diarias siguen en redes sociales son los medios de comunicación, frente a otro tipo de personajes influyentes o marcas (Estudio Anual Redes Sociales, 2020).

Los datos mostrados anteriormente, procedentes de dos estudios relevantes en el ámbito del uso de dispositivos electrónicos, de internet y de las redes sociales evidencian la influencia de la red y de las comunidades informativas virtuales en España; además la denominada sociedad de la información ha creado un mundo hiperconectado que ha permitido la comunicación en momentos de crisis social como el reciente confinamiento, derivado de la pandemia producida por la COVID19. Adicionalmente, como señala Casero-Ripollés (2020, p. 9) "El Covid-19 ha servido a los ciudadanos más alejados y menos interesados en las noticias para reconectarse con la información sobre asuntos públicos".

Sin embargo, por otro lado, ha derivado en la introducción y difusión pública de una ingente cantidad de información, a menudo descontextualizada y fragmentaria, con una serie de evidentes aspectos negativos como la infoxicación, es decir, el exceso de información o también la diseminación a gran escala de noticias falsas, fake news, que pueden crear confusión, desinformación o alarma social. Gelfert (2020) aporta una definición sobre este concepto y aclara que "las noticias falsas son la presentación deliberada de (típicamente) reclamos falsos o engañosos como noticias, donde los reclamos son engañosos por diseño" (Gelfert, 2020, p. 108).

En el caso concreto de la gestión de la crisis derivada de la COVID-19 compartimos la opinión de diversos autores para los que "los medios de comunicación y las redes sociales han producido una infodemia por la sobreinformación de muchos aspectos relacionados con la enfermedad" (Aleixandre-Benavent; Castelló-Cogollos; Valderrama-Zurián, 2020, p. 13).

Por ejemplo, sobre esta cuestión y desde el portal web Maldito Bulo, cuya función consiste en la monitorización y verificación de contenido web (Magallón-Rosa, 2018), han identificado 658 noticias falsas desde que se decretase la alarma por la COVID9 (Maldito Bulo, 2020). La naturaleza y tipología de estas noticias dudosas o directamente falsas es variada; con todo, es posible identificar dos grandes grupos principales de estas informaciones en la red: por un lado una gran cantidad de medicamentos milagrosos y falsamente efectivos contra el virus que provoca la enfermedad COVID19 y por otro diversas teorías conspirativas más o menos alocadas pero inquietantes sobre la naturaleza, el propósito o el origen del virus; a menudo las agencias verificadoras emitían sentencias sobre informaciones que se expandían en las redes sociales: por ejemplo, "la pandemia de COVID-19 no está causada por el 5G" (Maldito Bulo, 2020). No obstante, Rubin Chen y Conroy (2015) si establecen una clasificación de las fake news en relación al emisor. En ella establecen tres categorías esenciales "a) fabricaciones serias (descubiertas en los medios de comunicación principales o participantes, prensa amarilla o tabloides); b) engaños a gran escala; c) falsificaciones humorísticas (sátira de noticias, parodia, programas de juegos)" (Rubin, Chen, Conroy, 2015, p. 4)

En cualquier caso, el objetivo que persigue esta clase de información es variado, pero desde luego crean alarma entre la sociedad, pudiendo aumentar cierta histeria colectiva y alentar debates tóxicos que difieren de la realidad, para crear una sociedad desinformada.

Como se ha expuesto, la crisis sanitaria y social producida por la extensión del virus de la COVID-19 evidenció en todos los países y singularmente en España, un momento de máxima necesidad informativa clara y veraz, justo cuando las noticias falsas o la desinformación han tenido un efecto relevante sobre la población, especialmente en los inicios de la pandemia. Por ello, esta ha llevado a las distintas redes sociales a organizar y proponer herramientas para hacer frente a las noticias falsas. 0 , al menos, para intentar que se filtren el menor número de estas informaciones. Esta investigación se propone por tanto conocer, describir y definir esas herramientas, su naturaleza y su función en cada 
red social. En definitiva, el presente trabajo tiene como objetivo el análisis de las herramientas desarrolladas por Facebook, Instagram y Twitter en sus páginas web o portales en España durante la COVID-19, para ayudar al usuario a identificar los bulos, las noticias falsas o la desinformación.

\section{Estado de la cuestión}

En el apartado anterior, se ha hecho referencia al aumento del uso de las redes sociales y como se reclama entre el público español una mayor participación de los medios de comunicación en las redes sociales. Por analogía, el consumo de información a través de redes sociales viene a ser la evolución del modelo Mediterráneo o Pluralista Polarizado, con el que Hallin y Mancini (2004) definieron entre otros países a España y referido al papel de la prensa tradicional.

Para estos autores, este modelo Mediterráneo o Pluralista Polarizado se caracteriza por una prensa orientada hacia una élite minoritaria con tiradas de ejemplares relativamente cortas y una correspondiente importancia de los medios electrónicos (Hallin y Mancini, 2004). La proliferación de los medios de comunicación y la necesidad de alcanzar a más público masivo ha hecho posible que la desinformación se extienda dentro de del sistema mediático, donde, evidentemente, tiene mayor presencia en los contenidos de la esfera digital y en las redes sociales, "aunque no excluye que los medios tradicionales estén cada vez más optando por la creación de pseudo-contenidos de carácter límbico, desviándose hacia la otrora popular "tabloidización" en función de su competencia por la preferencia del consumidor (Aguaded y Romero-Rodríguez, 2015, p. 51)

La pseudo-información ha dejado la puerta abierta a las fake news. Esto es, el usuario se aleja de la información más objetiva y de calidad, se adentra en la esfera del espectáculo, la irracionalidad y de las emociones. En parte, este fenómeno se puede considerar una derivad total dentro del modelo informativo que viene asentándose desde la normalización de internet donde "El papel activo que antaño se defendía para los públicos-audiencias ha dado un giro de 180" (Real, Agudiez, Príncipe, 2007, p. 191). Es ahí donde prolifera la desinformación en el ámbito informativo. Obviamente estos fenómenos no son exclusivos de las redes sociales, es necesario señalar aquí la crisis del modelo informativo tradicional y de los medios en España, y su propia responsabilidad en esta cuestión, aunque ello excede los propósitos del presente trabajo. En definitiva, se puede considerar como sinónimo de falsedad emotiva "la distorsión deliberada de la realidad con el fin de crear y modelar la opinión pública e influir en las actitudes sociales. Una realidad en la que los hechos objetivos, las referencias fácticas, tienen menos influencia que las apelaciones a las emociones y a las creencias personales" (Olmo y Romero, 2019, p. 2)

Por su parte, autores como Brummette et al. (2018) también explicitan que existe una relación entre las fake news y las emociones, "la discusión de noticias falsas se lleva a cabo en redes en línea emocionalmente cargadas e ideológicamente similares" (Brummete et al. 2018, p. 510). Además de las emociones, Olmo y Romero (2019) indican que el propio funcionamiento de las redes sociales empuja al usuario a creer en las fake news; "brevedad y contundencia, velocidad y eficacia, conceptos que vuelven a situarse por encima de la verdad en la escala de valores" (Olmo y Romero, 2019, p. 3). Nelson y Taneja (2018) añaden un factor determinante, como es la voluntad y la predisposición del usuario, ambos autores explican que usar plataformas como Facebook no implica necesariamente asumir noticias falsas, ya que, según los datos de su estudio, "el tiempo que los usuarios de Real News pasaron en Facebook es solo un poco más alto que el tiempo promedio que todos los usuarios de Facebook pasaron en la plataforma" (Nelson y Taneja, 2018, p. 3733). Por tanto, la red social en sí misma no es un factor determinante, pero la predisposición emocional del usuario sí lo sería. Adicionalmente, Nielsen, Fletcher, Newman, Brennen y Howard (2020) han publicado un trabajo sobre como las personas acceden a la información durante la pandemia producida por el coronavirus, concluyen que los ciudadanos son conscientes de la información de las redes sociales es mucho menos confiable que la de los medios de comunicación.

Tandoc et al. (2018) advierten de la interferencia cada vez más habitual de las denominadas fake news dentro del ecosistema mediático, como una parte de este. Para estos autores, las noticias falsas llevan demasiado tiempo mezclándose con la información veraz y contrastadas; como consecuencia "para el consumidor normal de noticias, se ha vuelto cada vez más difícil distinguir entre lo que es verificable, basado empíricamente, y lo que es contenido falsificado provisto con la intención de engañar al lector" (Tandoc et al. 2018. p. 275). En este sentido, como señalan Lotero, Romero y Pérez (2018) "un modelo de comunicación de muchos a muchos, en el cual los usuarios también producen y comparten contenidos (prosumo), es un factor que profundiza el problema de la desinformación y las fake news" (Lotero, Romero, Pérez, 2018, p. 312-313).

Aquí destaca otro elemento del modelo Mediterráneo con el que precozmente caracterizaron Hallin y Mancini (2004) a España: la profesionalización del periodismo. Para estos autores, el periodismo en nuestro país está 
ligado al activismo político; además la autonomía para ejercer la profesión se puede ver limitada (Hallin y Mancini, 2004). De igual modo, la precariedad laboral de los periodistas es otro elemento determinante a la hora de ejercer la profesión, siendo la principal preocupación para los profesionales de la comunicación en España según determinó el Informe de la Profesión Periodística (2019). La importancia de los periodistas ante la oleada de información engañosa y la aparición de noticias falsas ha sido puesta de manifiesto repetidamente por diversos estudios; "los profesionales de la información y los medios de comunicación tienen una gran responsabilidad y deben ser capaces de proporcionar a la población la información objetiva basada en pruebas que contribuya a mejorar sus conocimientos sobre la enfermedad y reducir su incertidumbre, sobre todo los relacionados con las medidas preventivas (Aleixandre-Benavent; Castelló-Cogollos; Valderrama-Zurián, 2020, p. 13).

En esta línea, Ufarte-Ruiz, Galletero-Campos y López Cepada, reafirma la necesidad de la calidad e importancia de la información en tiempos de crisis al afirmar que "Los medios públicos deben convertirse en referentes ante los engaños y las fake news a medida que la situación del COVID-19 se intensifica en todo el mundo" (Ufarte-Ruiz, Galletero-Campos y López Cepada, 2020, p. 98).

\section{Metodología}

Como se ha señalado, el presente trabajo tiene como objetivo la identificación, la descripción y finalmente el análisis de las herramientas y las estrategias desarrolladas por las redes sociales Facebook, Instagram y Twitter durante la COVID-19 en sus portales o páginas web de inicio en España, para ayudar al usuario a identificar las noticias falsas. La selección de estas tres redes responde a los datos aportados por el Estudio Anual de las Redes Sociales, que señala que Facebook sigue siendo la red más conocida seguida de Instagram y Twitter (al igual que en el año 2019) (Estudio Anual Redes Sociales, 2020). En este sentido, la investigación pretende precisar las características externas generales de una población basándose en la observación de casos individuales, por lo que se establece dentro del marco general del método cualitativo (Sierra Bravo, 1998), priorizando los aspectos descriptivos e interpretativos. Ciertamente este estudio descriptivo de las herramientas y estrategias que Facebook, Instagram y Twitter emplean puede no ser totalmente trasladable a otras redes sociales, pero su importancia, enorme peso e influencia en la esfera comunicativa virtual permite establecer tendencias comunicativas claras respecto a la estructura de la información y a la priorización de fuentes oficiales y verificadas. Se ha llevado a cabo por tanto un análisis temático cualitativo (Guest, 2012) estableciendo categorías según la estructura y contenidos establecidos por cada red social respecto al COVID-19 en su portal web de internet. El proceso de codificación fue el resultado de las categorías iniciales surgidas de los objetivos del trabajo junto con otras que se inducen de la observación, la lectura y la interpretación directa de la web (Valles, 2000) en relación con la COVID-19 en las páginas de inicio de las redes sociales analizadas.

En cuanto a la limitación del objeto de estudio, el trabajo pone el foco sobre las herramientas que se han ido desarrollando por estas tres redes sociales, desde que se decreta el estado de alarma en España por la pandemia causada por la COVID-19, hasta el día 30 de junio de 2020, ya que las últimas novedades y cambios en la página de Twitter se dieron a conocer el 16 de junio y las de Facebook el 30 de junio. Durante este tiempo se consultaron y monitorizaron las redes sociales comprobándose cómo las tres plataformas fueron aumentando y completando la verificación de noticias y la estructura informativa de sus páginas de inicio; se trabajó así con la ultima versión de esas páginas, que se mantuvo después como estable y definitiva.

Junto al objetivo principal enunciado, este trabajo plantea un objetivo secundario: establecer si existen herramientas pasivas y herramientas activas en la detección de las fake news y clarificar su naturaleza. Este aspecto parte de la premisa de que las redes sociales, constituidas dentro de la denominada web 2.0, tienen como característica principal la interacción. Por lo tanto, se estudia las herramientas emplean las principales compañías de redes sociales para hacer llegar la información veraz al usuario, al mismo tiempo que se analiza el modo y el grado en que intenta hacer partícipe al usuario del proceso.

Para lograr materializar ambos objetivos, este estudio se ha planteado en tres fases. En primer lugar, en cada portal de entrada en las tres redes sociales se han identificado y recopilado las distintas herramientas y estrategias desarrolladas por Facebook, Instagram y Twitter. En la segunda fase, se lleva a cabo una descripción pormenorizada de cada una de las herramientas recolectadas durante la primera fase.

Finalmente, y en base a la funcionalidad revelada por la fase 2 , se analiza y se concluye si la herramienta en cuestión es unidireccional e informativa para el inter- 
nauta o si, de otra parte, permite la interactividad y la capacidad educativa de los usuarios.

\section{Resultados}

De acuerdo con lo establecido anteriormente en el desarrollo del proceso metodológico, se identifican herramientas web empleadas por Facebook, Twitter e Instagram en España; comenzando por las herramientas y estrategias que ha desarrollado Facebook para combatir las fake news durante la crisis de la COVID19. Se constata como esta red social ha elaborado dos fórmulas distintas. La primera de ellas, que es la que se muestra en la Figura 1, corresponde al Centro de información sobre el coronavirus (COVID19). Este espacio responde a una serie de características concretas centradas en la información contrastada y verificada. Para ello, la página nutre todos sus apartados de fuentes oficiales como el Gobierno de España, el Ministerio de
Sanidad o la Organización Mundial de la Salud. Gracias a estas fuentes compone los siguientes espacios:

a) "Actualizaciones del día". Recoge información sobre los nuevos casos y las principales noticias sobre la COVID-19 del día.

b) "Sugerencias comunes sobre prevención".

c) "Encuentra la ayuda que necesitas". Sugerencias de expertos y busca ayuda para ti o alguien que te importe.

d) "Más titulares". En esta última sección, se muestran noticias de medios de comunicación tradicionales, ya sean radio, prensa o televisión, sobre las últimas informaciones publicadas sobre la crisis sanitaria de la COVID-19.

Paralelamente a esta canal o espacio disponible que ha creado Facebook como centro de información, el 30 de junio lanzó una campaña específica con el fin de detectar noticias falsas. En concreto, se denominó

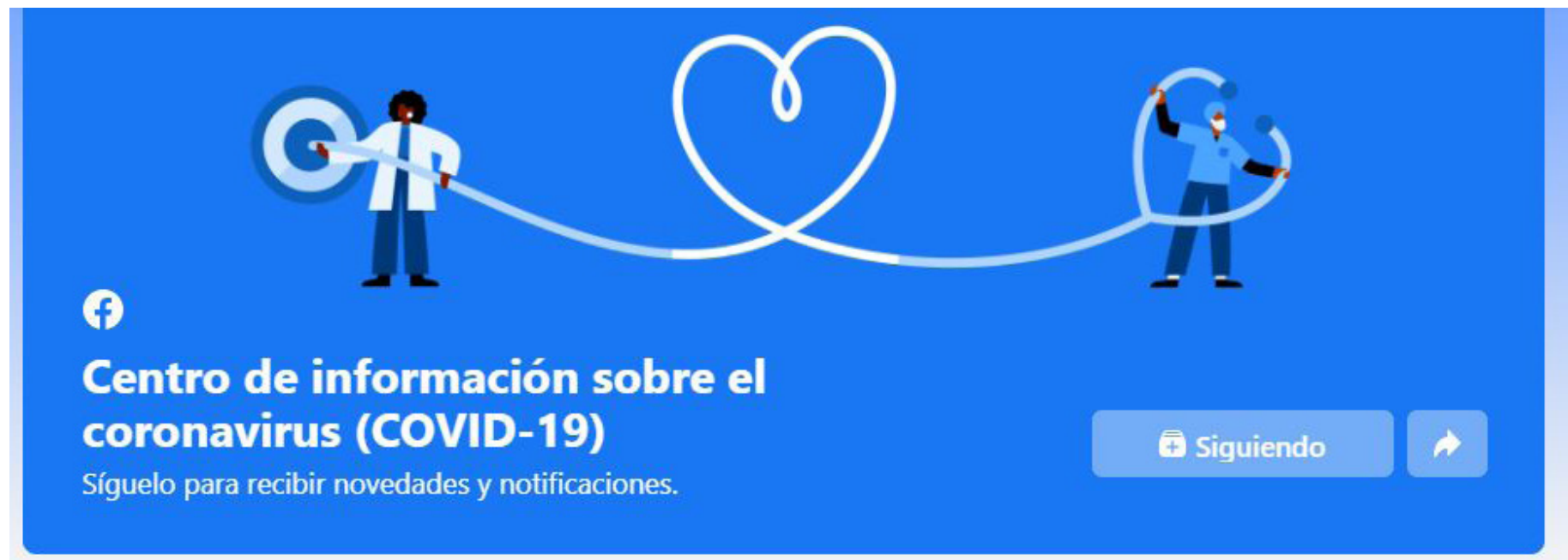

28 de julio de 2020

\section{Actualizaciones del día}

$\begin{array}{lll}\text { España } & & \\ \text { Casos nuevos } & \text { Ayer } & \text { Casos totales } \\ & +0 & 272421\end{array}$

Última actualización: hace 2 horas

Fernando Simón descarta que España esté sufriendo una segunda ola de COVID-19

Reino Unido desaconseja a sus ciudadanos viajar a Canarias y Baleares

Las residencias de ancianos españolas acumulan más de 19.600 7. muertes con coronavirus o síntomas compatibles, según datos de las CC.AA.

\section{Organizaciones sanitarias reconocidas}

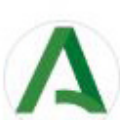

AGS Este de Málaga-Axarquía

Organización gubernamental

Seguir Ir al sitio web

Distrito de Atención Primaria Costa del Sol

Organización

$$
\text { Seguir Ir al sitio web }
$$

creditiodín. Salud Norte de Málaga

udNortemálags: Organización gubernamental

Seguir Ir al sitio web

Figura 1. Centro de información sobre el coronavirus. Facebook 29/07/2020. 

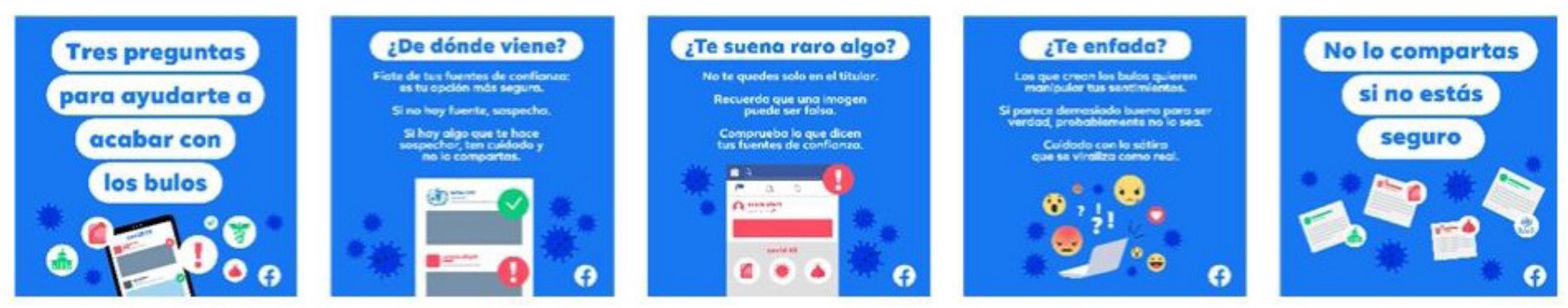

Figura 2. Campaña «Tres preguntas para ayudar a eliminar las noticias falsas», Facebook 28/07/2020.

"Tres preguntas para ayudar a eliminar las noticias falsas". Esta iniciativa parte de la premisa de ofrecer a las personas las herramientas para tomar decisiones bien documentadas sobre la información que ven online y de dónde proviene. La idea que subyace en esta campaña es la de hacer partícipe al usuario. A diferencia del caso del centro de información, donde se pone a disposición del usuario información ya verificada, con esta campaña que lleva a cabo Facebook se quiere crear una conciencia en el público, aleccionándole sobre como detectar la desinformación. En cierto sentido ofrece una función de alfabetización mediática sobre información en redes. Así, para ayudar al usuario a identificar qué diferencia una noticia falsa de una noticia contrastada, desde la red social apelan a los aspectos esenciales a la hora de identificar si el usuario está antes una fake news:

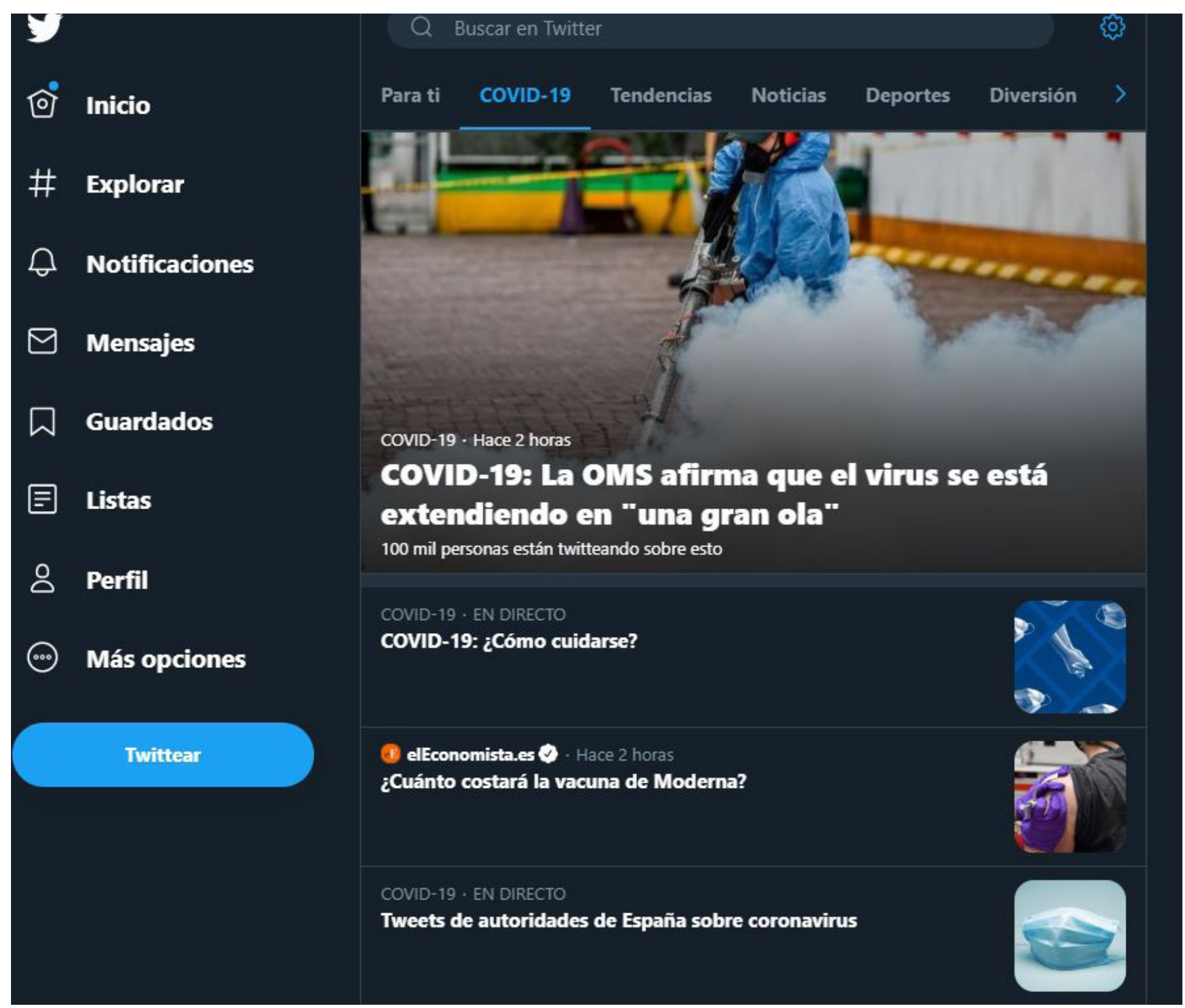

Figura 3. Pestaña COVID-19 en "Explorar". Twitter 28/07/2020. 
a) "¿De dónde viene? Si la fuente no está identificada, búscala".

b) "¿Qué falta? Conoce toda la noticia, no solo del titular".

c) "¿Cómo te hace sentir? La gente que crea noticias falsas trata de manipular nuestras emociones".

El usuario recibe esas cuestiones en el portal de ingreso a Facebook como se muestra en la Figura 2.

De forma muy similar ha actuado por su parte la red social Twitter. En primer lugar, y como se puede visualizar en la siguiente Figura 3, ha creado un espacio específico dentro de la pestaña "Explorar" dedicada a la COVID-19. Al igual que en el caso anterior, se trata de recopilar y ofrecer información cuyas fuentes sean oficiales o medios de comunicación tradicionales en principio de prestigio más reconocido. Como matiz, indicar que mientras que Facebook sólo incluía fuentes oficiales, aquí se incluyen otros medios de comunicación.

De esta forma, desde la plataforma del microblogging ofrece un espacio de noticias "seguras" a sus usuarios. Se trata de un centro de información que guarda alguna similitud con el que ha creado Facebook; la diferencia, más allá de la propia idiosincrasia de la propia red, en que se estructura de forma inversa a Facebook. En este caso, ofrece en primer lugar las últimas noticias sobre la pandemia y, seguidamente, lleva al usuario a un botón que abre una nueva página donde se pueden consultar recomendaciones de los especialistas de la salud sobre la COVID-19. En este último apartado todas las fuentes que allí se emplean son oficiales, ya sea el Gobierno de España o la Organización Mundial de la Salud.

Junto a esta herramienta, Twitter realizó una campaña centrada en la verificación de la información vinculada a la COVID-19. En este sentido, junto a la creación de la pestaña ya mencionada, se añadieron una serie de parámetros que ayudan a los usuarios a la verificación de las noticias permitiendo al tuitero ejercer una labor verificadora y activando el espíritu crítico con la información leída:

a) Verificación de cuenta COVID-19.

b) Expansión global del indicador de búsqueda COVID-19.

c) Una página dedicada al evento COVID-19.

d) Lanzamiento de un nuevo indicador de búsqueda dedicado \#KnowTheFacts.

e) Compromiso directo con organizaciones que trabajan para contener la amenaza.
Como se evidencia a partir de la descripción de la estructura anterior, se puede apreciar la implicación de estas grandes compañías tecnológicas respecto a ofrecer información contrastada a los usuarios. No obstante, como se ha señalado en los objetivos de este trabajo, también puede comprobarse que desarrollan una serie de estrategias que tienen como objetivo hacer partícipe al usuario en la identificación de las fake news. Si desde Facebook se había apostado por una estrategia centrada en ayudar al usuario a identificar qué es una fake news de qué no lo es, desde la red social del microblogging se desarrolla una estrategia distinta cuya raíz es la misma: hacer que el usuario cuestione ciertas informaciones, indague su procedencia y su propósito, convirtiéndolo en una fuente activa y crítica en la interpretación de la representación periodística. A diferencia del caso anterior, Twitter pone en cuestión aquellas informaciones que vienen de fuentes no verificadas o cuya validez de su autor u origen como experto en la materia del COVID19 esté puesta en cuestión.

En concreto, la red social ha creado la etiqueta que se muestra en la Figura 4, para aplicarla en estos tres casos:

a) Información engañosa: declaraciones o afirmaciones que han sido confirmadas como falsas o engañosas por expertos en la materia, como lo son las autoridades de salud pública.

b) Afirmaciones polémicas: declaraciones o afirmaciones en las que la precisión, veracidad o credibilidad de la aseveración es realmente cuestionada o desconocida.

c) Afirmaciones no verificadas: la información (que podría ser cierta o falsa) que aún no está confirmada al momento que se comparte.

En cualquier caso, desde el portal oficial de la red social Twitter, se emitió un comunicado el pasado 14 de julio indicando los motivos que hacen posible que un tuit sea considerado como información engañosa. A este respecto, desde la plataforma del microblogging se explica que "Para que un Tuit sea considerado como información engañosa, debe ser una afirmación de hecho (no una opinión), expresada definitivamente y con intenciones de influir en el comportamiento de los demás" (Twitter, 2020). Es decir, desde la empresa se remarca la importancia de respetar las opiniones, sea cual sea su fundamento. No obstante, esta definición se amplía con una serie de factores que determinan que una información sea considera como engañosa:

a) El origen, naturaleza y características del virus; 


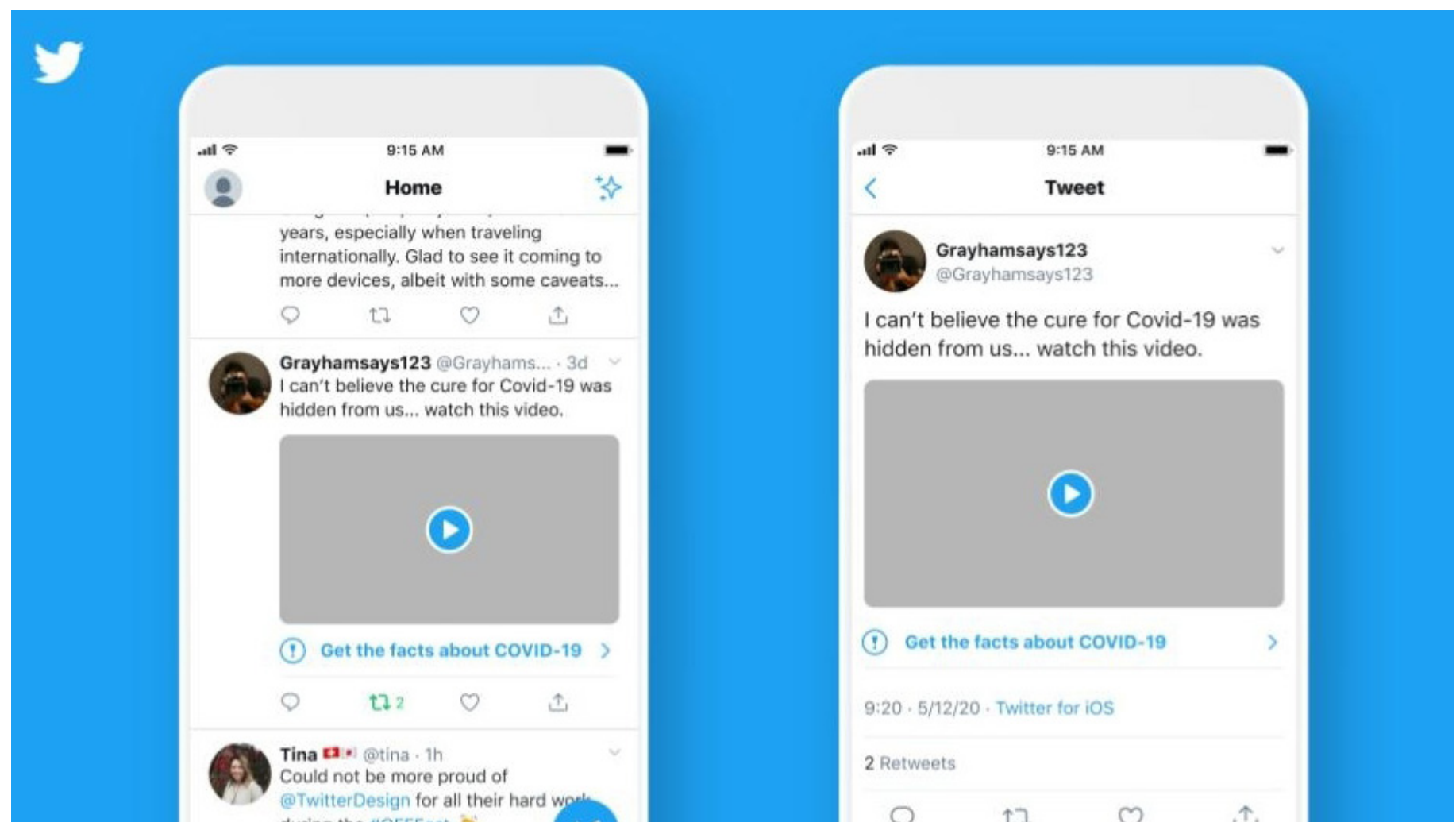

Figura 4. Ejemplo de etiqueta sobre posible información falsa. Fuente: Twitter.

b) Medidas preventivas, tratamientos/curas y otras precauciones;

c) La prevalencia de la propagación viral o el estado actual de la crisis;

d) Avisos oficiales de salud, restricciones, regulaciones y anuncios de servicio público;

e) Cómo las comunidades vulnerables se ven afectadas o responden a la pandemia.

Finalmente, y por lo que respecta a la tercera de las redes sociales analizadas, Instagram, ésta optó por adaptar los contenidos vinculados a la COVID-19 al propio marco de la red social. A este respecto, desde la red social de la imagen se presentó un enfoque más dinámico y educativo donde sus usuarios fuesen partícipes de la información, al mismo tiempo que se anunció la eliminación de aquellas cuentas poco fiables. Ese acercamiento directo, activo y dinámico responde a la propia naturaleza de la red, con predominio de la imagen y público más joven. De esta manera, desde la red social se hizo público un comunicado donde se explican los siguientes puntos de la estrategia contra la lucha de las fake news en Instagram:

a) Más recursos educativos en la búsqueda de Instagram (Figura 5).

b) Stickers para promocionar información precisa. c) Eliminación de cuentas relacionadas con el COVID19 de las recomendaciones, a menos que las haya publicado una organización de salud confiable.

d) Implementación del sticker de donación en más países y una sección para que las personas encuentren organizaciones sin fines de lucro relevantes para apoyar.

e) Creación de una historia compartida para que las personas que practican el distanciamiento social se conecten con otras por medio del sticker "En casa".

f) Nueva función para explorar Instagram a través de un videochat con amigos.

Como se extrae de la relación de aspectos desarrollados por la red social de la imagen, se trata de hacer partícipe al usuario a partir de las herramientas disponibles dentro del propia red. De igual modo, se opta por ofrecer información de calidad basada en fuentes fiables, así como por la eliminación de cuentas dudosa. Singularmente, este último aspecto es una constante en todas las redes sociales. En términos generales se observa que estas tres grandes redes sociales han actuado no sólo como meras transmisoras sino como especialistas en información, con capacidad reactiva y proactiva, de forma en cierto sentido análoga a la figura tradicional periodística del GateKeeper, esto es, un intermediario entre una enorme cantidad de fuentes de información y 
noticias y los usuarios de la red, y actuando como verificador de esas noticias y como mediador.

\section{Conclusiones}

La presente investigación planteó como objetivo principal la identificación, descripción y el análisis de las herramientas y estrategias desarrolladas por Facebook, Instagram y Twitter durante la COVID-19 en España para ayudar al usuario a identificar las fake news; y uno secundario, esto es, comprobar si son herramientas activas e interactivas con el usuario en la detección de las noticias falsas. De forma general puede concluirse

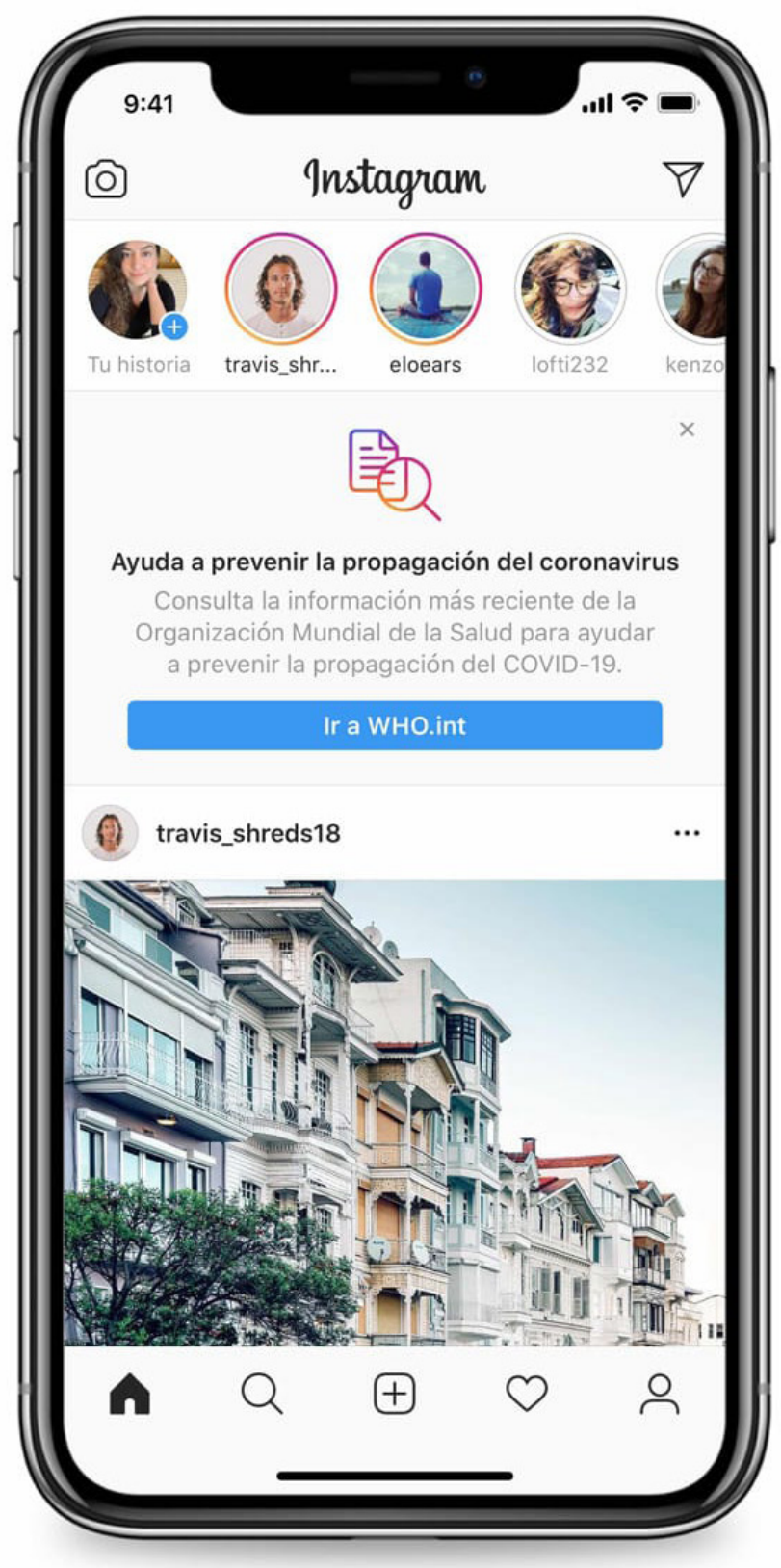

Figura 4. Representación búsqueda de Instagram sobre la COVID-19. Fuente: Instagram. que se evidencia que estas redes sociales han puesto en marcha estas herramientas específicas, con peculiaridades en cada red, y que estas plataformas involucran de diversas formas al usuario para que aprenda y entienda la naturaleza de las informaciones sobre la pandemia.

Las tres redes sociales analizadas, Facebook, Twitter e Instagram ubican en lugar prominente herramientas para luchar contra las fake news, evidenciando la preocupación existente por parte de las redes sociales por la difusión de noticias falsas, algo que mina la credibilidad del canal. La implicación de las grandes plataformas de redes sociales en esta cuestión es una clara conclusión de este estudio. Puede ser motivo de discusión los motivos para ello, aunque aquí apuntamos de forma deductiva a dos cuestiones principales. Por un lado, reducir a la mínima cantidad el posible consumo de fake news por parte de los usuarios. También se evidencia que estos gigantes tecnológicos buscan consolidar a sus públicos, evitar un problema de fuga de usuarios y pérdida de credibilidad; es decir, las marcas intentan evitar que cualquiera de ellas sea sinónimo de fake news. Se observa entonces cómo estos actores tecnológicos analizados se han involucrado activamente en la alfabetización mediática, incrementando la credibilidad de la comunicación digital, evitando la pérdida de confianza en la red como medio informativo, y en definitiva apuntalando su futuro empresarial.

En segundo lugar, la apuesta clara de todas ellas por las fuentes oficiales y de prestigio reconocido como medios de comunicación, ya sean prensa, digitales, radio o televisión. En cualquier caso, las noticias que incluyen las redes analizadas parten siempre de medios ampliamente reconocidos y todos los consejos de salud son derivados a organizaciones capacitadas para responder, como el Ministerio de Sanidad o la Organización Mundial de la Salud.

En cuando al objetivo secundario, podemos afirmar que todas las redes sociales aplican distintas herramientas activas y pasivas a la hora de hacer frente a las fake news relacionadas con la COVID-19. En todas ellas, la eliminación de cuentas susceptibles o posiblemente engañosas es una constante. Por su parte, dentro también de las herramientas pasivas, podemos ver los centros de noticias creados por Facebook y Twitter, así como el aviso de Instagram para que los usuarios acudan directamente al perfil de la Organización Mundial de la Salud.

Es destacable también las distintas estrategias empleadas por cada uno de estos portales. Facebook e Instagram basan sus estrategias activas en intentar educar al usuario en lo que respecta al reconocimiento de una fake news frente a una noticia veraz. Sobre todo, 
en el caso de Facebook, observamos todo un despliegue visual que hace que el usuario se pueda implicar y sea partícipe del proceso. Al mismo tiempo, Instagram integra dicha estrategia educativa en base a stikers y otra serie de recursos propias de su red social. En algunos casos, como en los momentos más difícil del confinamiento, con el sticker "En casa". Por su parte, Twitter apuesta por una estrategia más rotunda; en este sentido, esta red ha optado por marcar noticias con la etiqueta "obtengan los datos sobre COVID-19" con el fin de catalogar la información tuiteada como posiblemente engañosa. También da la opción al propio usuario de indicarlo.

Las redes sociales examinadas apuestan por dar información de calidad a sus usuarios al mismo tiempo que buscan forma de educar al usuario para identificar qué es una fake news. Como discusión de los resultados puede aportarse que sería necesario seguir implementado estas estrategias, ya que cada día se evidencia más que los bulos y la desinformación pueden convertirse en un problema social. Por lo tanto, las principales redes sociales deberían de seguir trabajando en la creación de canales seguros de información, al mismo tiempo que insisten en la implementación de campañas para la educación de los usuarios en estos términos. En este sentido, sería interesante, que al igual que un usuario tiene que aceptar la política de privacidad cuando crea un perfil en dicha red social, antes de empezar a publicar y compartir información, debería también ser informado sobre qué es una noticia falsa y cuáles son los pasos para identificarlas. En todo caso la tendencia observada, pero que debe ser corroborada en futuros estudios, es que las herramientas del fact-checking pueden cumplir funciones en cierta medida asimilables a la tradicional figura periodística del gatekeeper, para emular la credibilidad de los medios tradicionales.

Otro aspecto a discutir es que la profesión periodística, aunque proporcionase una información veraz a la ciudadanía, cuestión que por otra parte no siempre sucede, si las redes sociales no ponen a disposición de los usuarios herramientas para identificar y canalizar la información veraz y contrastada, crea desconfianza en el sistema mediático, pilar esencial en un sistema democrático, y el trabajo veraz realizado por los profesionales del mundo de la comunicación queda invalidado o limitado; esto se debe a que todo el esfuerzo comunicativo que se pueda llevar a cabo no alcanza al público masivo si interfieren las noticias falsas, ya sea a modo de post de Facebook o Instagram o como tuit; en definitiva todo ello puede generar una gran desconcierto entre la pobla- ción, viralizarse y relegar y esconder la información real y contrastada al último lugar de la sección de noticias.

Podemos concluir, que "si las nuevas generaciones obtienen su información de redes sociales y otros recursos en línea, deben aprender a decodificar lo que leen" (Fernández, 2017, p.75). Medios, redes sociales y el propio usuario juegan un papel determinante a la hora de limitar y mediar a las noticias falsas.

\section{Referencias}

Aguaded, I., y Romero-Rodríguez, L. M. (2015). Mediamorfosis y desinformación en la infoesfera: Alfabetización mediática, digital e informacional ante los cambios de hábitos de consumo informativo. Education in the Knowledge Society, 16(1), 44-57.

Aleixandre-Benavent, R., Castelló-Cogollos, L., y Valderrama-Zurián, J.-C. (2020). "Información y comunicación durante los primeros meses de Covid-19. Infodemia, desinformación y papel de los profesionales de la información. Profesional de la información, 29(4), 1-17.

Asociación de la Prensa de Madrid. (2019). Informe de la Profesión Periodística 2019. Asociación de la Prensa de Madrid.

Brummette, J., DiStaso, M., Vafeiadis, M., y Messner, M. (2018). Read All About It: The Politicization of "Fake News" on Twitter. Journalism \& Mass Communication Quarterly, 95(2), 497-517.

Casero-Ripollés, A. (2020). Impact of Covid-19 on the media system. Communicative and democratic consequences of news consumption during the outbreak. El profesional de la información, 29(2), e290223.

En Instagram, protegemos, apoyamos y mantenemos informadas a las personas. (24 marzo 2020). Instagram. https://about.instagram. com/blog/announcements/coronavirus-keeping-people-safe-informed-and-supported-on-instagram/

Facebook. (20 julio 2020). Facebook. https://about.fb.com/news/

Fernández-García, N. (2017). Fake news: una oportunidad para la alfabetización mediática. Nueva Sociedad(269), 66-77.

Gelfert, A. (2018). Fakes News: A Definition. Informal Logic, 38(1), 84-117.

Guest, G. (2012). Applied thematic analysis. Sage.

Hallin, D., y Mancini, P. (2004). Comparing Media Systems.Three Models of Media and Politic. Cambridge University Press.

IAB.Spain. (2020). Estudio de Redes Sociales 2020. IAB.Spain.

Instituto Nacional de Estadística. (2019). Encuesta sobre Equipamiento y Uso de Tecnologías de Información y Comunicación en los Hogares. Instituto Nacional de Estadística

Lotero-Echeverri, G., Romero-Rodríguez, L. M., y Pérez-Rodríguez, M. A. (2018). Fact-checking vs. Fake news: Periodismo de confirmación como recurso de la competencia mediática contra la desinformación. Index.comunicación, 8(2), 295-316.

Magallón-Rosa, R. (2018). Nuevos formatos de verificación. El caso de Maldito Bulo en Twitter. Sphera Publica, 1(18), 41-62.

Maldita.es. (17 julio 2020). El coronavirus y sus bulos. Maldita.es. https://maldita.es/malditobulo/2020/05/06/coronavirus-bulos-pandemia-prevenir-virus/

Nelson, J. L., y Taneja, H. (2018). The small, disloyal fake news 
audience: The role ofaudience availability in fake news consumption. New media \& society, 20(10), 3720-3737.

Nielsen, R. K., Fletcher, R., Newman, N., Brennen, J. C., y Howard, P. N. (2020). Navigating the 'Infodemic': How People in Six Countries Access and Rate News and Information about Coronavirus. Reuters Institute for the Study of Journalism.

Olmo y Romero, J. A. (2019). Desinformación: concepto y perspectivas. CIBER elcano (43). http://www.realinstitutoelcano.org/wps/ portal/rielcano_es/contenido?WCM_GLOBAL_CONTEXT=/elcano/ elcano_es/zonas_es/ari41-2019-olmoromero-desinformacion-concepto-y-perspectivas

Real Rodríguez, E., Agudiez Calvo, P., y Príncipe Hermonso, S. (2007). Periodismo ciudadano versus Periodismo profesional: ¿somos todos periodistas? Estudios sobre el Mensaje Periodístico, (13), 189-212.

Rubin, V. L., Chen, Y., y Conroy, N. K. (2015). Deception Detection for News: Three Types of Fakes. ASIS\&T Annual Meeting: Information Science with Impact: Research in and for the Community, 71-74.

Sierra Bravo, R. (1998). Técnicas de Investigación Social Teoría y ejercicios. Editorial Paraninfo.

Tandoc Jr, E., Ling, R., Westlund, O., Duffy, A., Goh, D., y Wei, L. Z. (2018). Audiences' acts of authentication in the age of fake news: A conceptual framework. New media \& society, 20(8), 2745-2763.

Coronavirus: Mantente Seguro e Informado en Twitter (15 julio 2020). Twitter. https://blog.twitter.com/es_la/topics/company/2020/coronavirus-mantente-seguro-e-informado-en-twitter.html

Ufarte-Ruiz, M. J., Galletero-Campos, B., y López-Cepeda, A. M. (2020). "Fact-Checking, a Public Service Value in the Face of the Hoaxes of the Healthcare Crisis". Trípodos, 47(1), 87-103.

Valles, M. S. (2000). Técnicas cualitativas de investigación social. Síntesis Editorial.

\section{CV}

Javier Bustos Díaz. Es Profesor Ayudante Doctor en ESIC Business and Marketing School. Licenciado en Periodismo (2012) y Máster en Investigación en Comunicación Periodística (2013). En su carrera académica ha publicado 8 artículos dentro del Scimago Journal $\&$ Country Rank centrados en la comunicación política, sobre todo dentro de las redes sociales. De igual modo, ha publicado una decena de capítulos de libro sobre comunicación política, así como sobre las nuevas plataformas audiovisuales y la televisión, en editoriales como Tirant lo Blanch, McGraw-Hill, Gedisa, Tecnos o Pirámide entre otras.

Francisco Javier Ruiz del Olmo. Es Profesor Titular de la Universidad de Málaga, España. Desarrolla su labor docente e investigadora en las Facultad de Ciencias de la Comunicación. Investiga los modelos comunicativos de los medios audiovisuales y las formas de representación audiovisual contemporáneos, así como los usos técnicos y sociales de éstos; una segunda línea de investigación se relaciona con la comunicación y los nuevos medios. Ambas líneas de trabajo tienen el común el interés prioritario por las metodologías cualitativas en el análisis del audiovisual. ocm Observatorio

\section{https://observatoriocibermedios.upf.edu/}

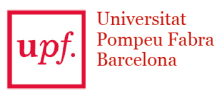

Departamento de Comunicación
Grupo DigiDoc

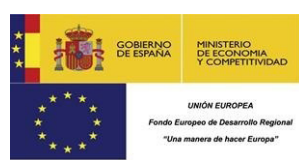

El Observatorio de Cibermedios es una producción del Grupo de Investigación en Documentación Digital y Comunicación Interactiva (DigiDoc) del Departamento de Comunicación de la Universitat Pompeu Fabra.

El Observatorio de Cibermedios (OCM) forma parte del proyecto del Plan Nacional "Narración interactiva y visibilidad digital en el documental interactivo y el periodismo estructurado". RTI2018-095714-B-C21 (MINECO/FEDER), Ministerio de Ciencia, Innovación y Universidades (España). 